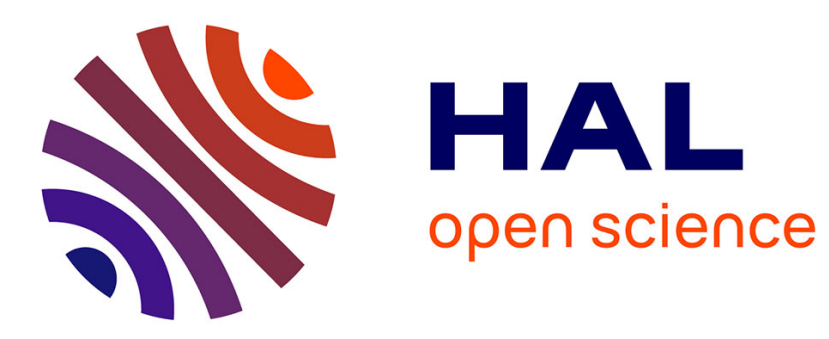

\title{
Distributed Creativity in Play
}

\author{
Andrew M Webb, Katta Spiel, Z O Toups, Bill Hamilton, Nic Lupfer, Ross A \\ Graeber, Wendy Mackay
}

\section{To cite this version:}

Andrew M Webb, Katta Spiel, Z O Toups, Bill Hamilton, Nic Lupfer, et al.. Distributed Creativity in Play. ACM 2019 - 12th Creativity and Cognition Conference, Jun 2019, San Diego, CA, United States. pp.714-721, 10.1145/3325480.3326554 . hal-02276985

\section{HAL Id: hal-02276985 \\ https://hal.science/hal-02276985}

Submitted on 3 Sep 2019

HAL is a multi-disciplinary open access archive for the deposit and dissemination of scientific research documents, whether they are published or not. The documents may come from teaching and research institutions in France or abroad, or from public or private research centers.
L'archive ouverte pluridisciplinaire HAL, est destinée au dépôt et à la diffusion de documents scientifiques de niveau recherche, publiés ou non, émanant des établissements d'enseignement et de recherche français ou étrangers, des laboratoires publics ou privés. 


\section{Distributed Creativity in Play}

\begin{tabular}{|c|c|}
\hline Andrew M. Webb & Katta Spiel \\
\hline Centrum Wiskunde \& & TU Wien \\
\hline Informatica (CWI) & Vienna, Austria \\
\hline $\begin{array}{l}\text { Amsterdam, Netherlands } \\
\text { andrew.webb@cwi.nl }\end{array}$ & katta@igw.tuwien.ac.at \\
\hline Z O. Toups & Nic Lupfer \\
\hline Bill Hamilton & Interface Ecology Lab \\
\hline $\begin{array}{l}\text { Computer Science Dept. } \\
\text { New Mexico State University } \\
\{\text { z,bill\}@cs.nmsu.edu }\end{array}$ & $\begin{array}{l}\text { Texas A\&M University } \\
\text { nic@ecologylab.net }\end{array}$ \\
\hline $\begin{array}{l}\text { Ross A. Graeber } \\
\text { ross.graeber@gmail.com }\end{array}$ & $\begin{array}{l}\text { Wendy E. Mackay } \\
\text { Univ. Paris-Sud, CNRS, } \\
\text { Inria, Université Paris-Saclay } \\
\text { Orsay, France } \\
\text { mackay@Iri.fr }\end{array}$ \\
\hline
\end{tabular}

This is the author's version of the work. It is posted here for your personal use. Not for redistribution.

The definitive Version of Record was published in Proceedings of the ACM Creativity and Cognition Conference (C\&C '19), June 23-26, 2019, San Diego, CA, USA O2019 Copyright is held by the owner/author(s).

ACM ISBN 978-1-4503-5917-7/19/06.

https://doi.org/10.1145/3325480.3326554

\begin{abstract}
Our objective is to explore distributed forms of creativity that arise in play to help guide and foster supportive research, game design, and technology. This workshop seeks to bring together researchers, game designers, and others to examine theories of creativity and play, game design practices, methods for studying creativity in play, and creative play experiences. Participants will present work, video prototype, discuss topics, and contribute to outcomes.
\end{abstract}

\section{CCS Concepts}

-Human-centered computing $\rightarrow$ Collaborative and social computing; $\mathrm{HCl}$ design and evaluation methods;

\section{Author Keywords}

games; social creativity; collaboration

\section{Introduction}

Play and creativity are intertwined. Play involves imagination and curiosity wherein players explore potential actions and realities [25]. This requires divergent thinking [23] and creative choice. In collaborative play, creative contributions are distributed among players. For example, in tabletop role-playing games, such as Dungeons \& Dragons [3, 20], players verbalize actions of their characters, adding to the generation of shared narrative. Sawyer and DeZutter iden- 


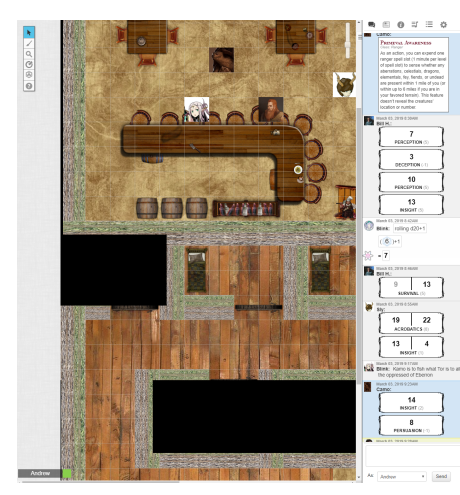

Figure 1: The Roll20 interface: tool palette in top-left; virtual tabletop in middle; and chat on right with dice roll results and non-verbal player conversations.

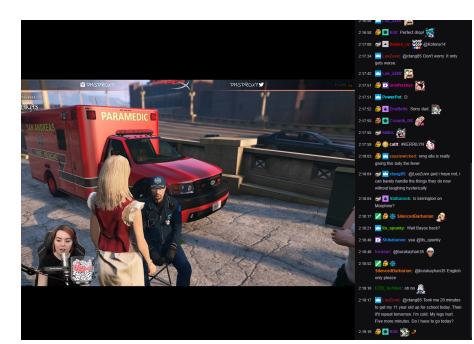

Figure 2: Twitch interface: game play video of online role-playing between two characters (left) and viewer chat (right).

\footnotetext{
${ }^{1}$ https://roll20.net

${ }^{2}$ https://www.twitch.tv

${ }^{3}$ https://help.twitch.tv/s/article/

how-to-use-clips
}

tify this as distributed creativity - "where individuals within groups contribute ideas often towards a common goal" [26]

Distributed creativity is not limited to players in the same physical space. Increasingly popular web-based platforms, such as Roll20 ${ }^{1}$ (Figure 1) and Twitch $^{2}$ (Figure 2), connect players from all over the world in shared play experiences. They offer opportunities to design for and study distributed creativity in situated and digitally-mediated play contexts. However, we suspect that qualities of these online spaces, their designs, and associated technologies affect distributed creativity. These spaces promote creative contributions through designs that increase participant agency or limit involvement through technological constraints. For example, Twitch's Clips $^{3}$ feature enables viewers to creatively curate interesting play moments during a live stream. Clips are shared in the chat, adding to the social play experience.

This workshop explores aspects of distributed creativity in play. We bring together $\mathrm{HCl}$ researchers, game designers, players, and other interested participants. The primary objectives of this workshop are to:

- identify characteristics of distributed creativity in play; - critically reflect on how design and technology draw upon, enable, limit, or negate these characteristics;

- share methodologies, practices, and environments for supporting and studying distributed creativity in play;

- foster future collaborations on workshop topics.

\section{Related Work}

Creativity is a hard term to define often leading to misguided attempts at broad explanations [7, 9]. We consider two specific forms of creativity identified by Kaufman and Beghetto [14]: little-c-everyday creativity arising from social situations; and mini-c_- "novel and personally meaningful interpretation of experiences, actions, and events." We foresee that little-c and mini-c arise in play as players engage in personal creative acts with others. This results in social creativity [8] as individuals interact towards cohesive group play, as in tabletop role-playing games.

When studying distributed creativity, $\mathrm{HCl}$ research focuses on collaborative, product-oriented definitions and domains [9]. According to Sawyer and DeZutter [26], "understanding distributed creativity requires an empirical focus on the moment-to-moment interactional process of the group, and how that collaborative, improvisational process leads to distributed creativity." We similarly see creativity in play as processual. For example, even in highly linear video games with specific narratives, players choose how to play [1, 25], making creative choices in how they advance the story.

Sociologist and psychologist study the effects of games and play on creativity $[2,5,12,24]$. A significant emphasis is given to how play affects the learning, social growth, and creativity of children $[12,24]$. Still, the Csikszentmihalyis investigated how adults enter creative flow states in both enjoyable work and play [5]. Bowman et al. argue for more studies of play and creativity with the increasing popularity of video games [2]. This workshop seeks to bring together knowledgeable parties to advance our understandings of distributed and social creativity in play.

\section{Key Topics and Questions}

This workshop explores the following topics and questions.

\section{Play Contexts with Distributed Creativity}

We invite submissions that identify one or more contexts involving distributed creativity in play. Below are examples.

Tabletop games (e.g., Dungeons \& Dragons, the board game Pandemic) facilitate distributed creativity. Players 


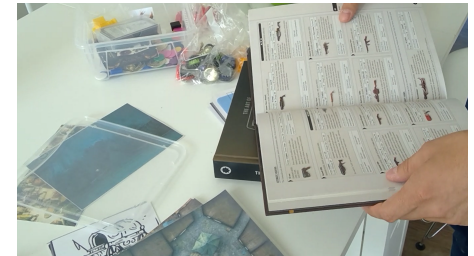

Figure 3: Examples of physical artifacts used in tabletop

role-playing games: maps, rule books, tokens, cards, bottle caps, and imagery.

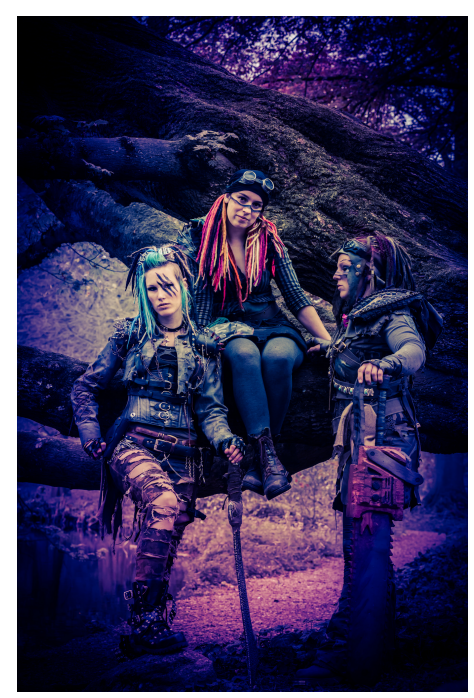

Figure 4: Live action role-players from Elfia Haarzuilen 2014. Their gear is coordinated to fit together into a shared narrative.

Photo by Qsimple [https: //www.flickr.com/photos/qsimple]. engage in collaborative storytelling and problem-solving experiences where creative choice is constrained by rules.

In role-playing games, players contribute to a story through voicing the actions and speech of characters in an imaginary world. These games are performative and improvisational [19]. The story is not entirely free-form; game rules and mechanics determine outcomes of actions [25]. For example, a player states that their character performs an acrobatic move to swing from a chandelier. The player rolls dice to determine success or failure. Improvisational creativity in these games is distributed and mediated by game elements and artifacts (Figure 3 ), such as maps and random generators [31].

In board games, the experience is often (but not always) less free-form and more constrained by game rules [21,22]. Players make choices within the rules, working toward an objective. The game's theme can help lead players to construct their own narratives during play, a creative process.

Recently, digitally mediated play of tabletop games through online platforms has emerged. Such platforms enable collaborative play for those who are geographically distributed. While these platforms contain means for communication (e.g., chat, voice, video) and shared virtual tabletops, they vary in the types of collaboration and play that they enable. We expect that this influences creative opportunities in play.

Modern live action role-play (larp) stems from tabletop roleplaying games [6]. From comparatively short scenario play to large multi-day events with several thousand participants, larps cover any type of embodied role-play that creates a closed narrative engagement between players (Figure 4). Players exhibit distributed creativity in their interactions with others, constructing a shared experience through collaboratively maintaining immersion and integrity of a play sce- nario [30]. Subsequently, this form of playful collaboration has been deemed potentially useful in education [10] as well as participatory design [13].

Game play live streaming, as primarily manifest through the popularity of Twitch, has emerged as a media practice for shared play experiences in participatory communities [11]. Modalities such as text chat and audience polls enable participants to engage in creative choice by making suggestions to remote players $[11,17]$. Distributed participants contribute creative works that add to game narrative, setting, and community $[11,17]$. Other emerging live streaming paradigms, such as "Twitch Plays" [17] and audience participation games [28], enable direct participant engagement in creative play. New modalities offer potential to further the creative ways distributed audiences participate in play [18].

\section{Methods for studying creativity (in play)}

We invite works that present methods for studying creativity in play, specifically little-c and mini-c. A general challenge of studying creativity is defining what is being studied. The creative cognition approach considers that creativity constitutes a number of different cognitive processes [7]. These processes are associated with different forms of creativity, such as generating new designs or improvising notes in a jazz performance. We posit that distributed creativity in play involves particular cognitive processes, such as those stemming from imagination and exploration. Thus, we need both new methods as well as adaptation of existing approaches.

In drawing upon existing methods for studying creativity, we could adapt survey metrics for creativity support tools [4] to gather and compare subjective experience data after play or use quantitative metrics of novelty, diversity, and quantity of ideas [15] to analyze creative choices made during play across all players. Approaches that rely on expert ratings of products $[27,29]$ seem less appropriate for play. 


\section{Participants \& Position Papers}

Maximum number of participants: 25. Participants are selected on the basis of the position papers (2-4 pages).

Position papers: This workshop calls for position papers related to the key topics and questions. Accepted participants are encouraged to bring interactive experiences to share at the workshop. We will publish (with author permission) final versions of the position papers on the workshop website.

\section{Duration: 1 full day.}

\section{Announcement \& recruit-}

ment: We will announce this workshop on a dedicated website providing a more thorough description and on mailing lists (e.g., $\mathrm{CHI}$ Announcements). We will contact local game studios, such as Renegade and Sony San Diego. We will actively recruit participants through our personal networks.
How does game design affect distributed creativity? We invite submissions that consider the effects of game design on creativity. This includes identifying and deriving game rules and mechanics that support creative acts in play. For example, in Dungeon World [16], a tabletop role-playing game, authorial control over the story is distributed between the players and the game master (referee) using rolls of two 6 -sided dice that determine the outcome of actions; values range between 2 and 12, with a higher probability of middle numbers. On a $10_{+}$, the player determines what happens; on a 7-9, control is shared; and on a $6-$, the game master determines what happens. In digitally mediated play, game designers make use of technology and software to facilitate distributed creativity. This includes web-based platforms, like Roll20 and Twitch, that enable distributed play. Features, such as collaborative drawing tools or communication modalities, give participants agency to express ideas and take action in creative play.

\section{Tentative Schedule}

The workshop tentatively has the following structure:

$$
\begin{aligned}
& \text { - 8:30 AM - Welcome \& Introduction } \\
& \text { - 9:00 AM - Show-and-Tell } \\
& \text { - 11:30 AM - Lunch } \\
& \text { - 1:00 PM - Prototyping Session } \\
& \text { - 4:00 PM - Prototype Presentations } \\
& \text { - 5:00 PM - Wrap-up Discussion }
\end{aligned}
$$

Welcome \& Introduction

Participants introduce themselves. Organizers present objectives of the workshop to situate the day's activities.

\section{Show-and-Tell}

Authors of position papers present their work, followed by a discussion. This may include technology demos or partici- pation in play experiences. Participants are encouraged to express topics for the prototyping session.

\section{Prototyping}

Participants break out into groups to video prototype play experiences with distributed creativity. Organizers split evenly amidst the groups to guide prototyping and time management. Prototypes are created with Video Clipper, an iPad application for rapid video prototyping developed by Wendy Mackay and her group. A tutorial is presented after forming groups.

Prototyping Presentations

Each group presents their video prototype(s). They are asked to explain how distributed creativity is supported (or not), describe their design rationale, and identify potential issues and challenges. If participants agree, video recordings of presentations are collected as documentation.

\section{Wrap-up Discussion}

The workshop concludes with a wrap-up discussion. We invite participants to discuss valuable lessons they learned and open questions that remain. We encourage discussion of future work towards establishing potential collaborations.

\section{Workshop Outcomes}

We expect the following outcomes from the workshop:

- participants will develop increased knowledge and understanding of others' research and practices in the space of distributed creativity in play;

- an archive of position papers on the workshop topics;

- an archive of annotated video prototypes; and

- concrete plans for future collaborative research.

Participants will leave the workshop with better understandings of distributed creativity in play and directions for fu- 


\section{Requirements}

Required facilities: This workshop will benefit from taking place in a local design studio. We require a standard meeting space for joint work (large format TV or projector) with additional space for break-out groups. Additionally, a playful, visually aesthetic space offers creative opportunity for shooting video prototypes.

\section{Required materials: We} require materials for prototyping including markers, pens, scissors, tape, paper (multi-colored), post-it notes, transparent sheets, and flipcharts. Some materials will be provided by the facilitators.

\section{Optional Dinner \&} Games

Following the workshop, we will host an optional dinner and games event for workshop participants and others (as space is available). ture work. The organizers will collaborate with participants to produce a write-up of workshop activities and lessons learned. We will share this write-up on the workshop website. With permission, we will publish video prototypes on the website along with presentations.

\section{Organizers}

Andrew Webb is an ERCIM Postdoctoral Fellow at CWI in the Distributed and Interactive Systems group. A central theme of his research is how new interactive environments can support creativity. He is presently investigating the design of seamful media spaces for distributed tabletop roleplaying games. He is actively involved in the Creativity \& Cognition conference, serving on the program committee, co-chairing posters and demos, and publishing papers.

Katta Spiel researches marginalised perspectives in interaction design, often with a focus on playful engagements at TU Wien. Katta's most recent work centered on the experiences of autistic children with technologies and including their first-hand perspectives. They also have several years of experience as a game designer for the collaboratively created and maintained Discworld MUD.

Z O. Toups is an Associate Professor of Computer Science at New Mexico State University, where they direct the Play \& Interactive Experiences for Learning Lab. Z's work is primarily concerned with collaboration in game interfaces, looking at how groups of players plan strategy and communicate tactics. They apply this work to wearable computer systems and mixed realities. $Z$ is well played in digital games and tabletop RPGs and board games.

Bill Hamilton is an Assistant Professor of Computer Science at New Mexico State University, where he directs the Participatory Live Experiences Lab. Bill's work investigates the formation of live media communities and how the design of media technologies can impact participation in situated play, education, and political contexts. Bill also investigates the design of collaborative games.

Nic Lupfer is a doctoral candidate at Texas A\&M University. His doctoral research investigates new ways for supporting collaborative design ideation among student teams. Nic is also an avid participant in multiple local and global game jams and serves as a mentor in the local student International Game Developers Association chapter.

Wendy Mackay is a Research Director, Classe Exceptionnelle, at Inria, France, where she heads the ExSitu (Extreme Situated Interaction) research group in HumanComputer Interaction at the Université Paris-Saclay. After receiving her Ph.D. from MIT, she managed research groups at Digital Equipment and Xerox EuroPARC, which were among the first to explore interactive video and tangible computing. She recently served as Vice President for Research at the University of Paris-Sud. Wendy is a member of the ACM CHI academy, is a past chair of ACM/SIGCHI, chaired $\mathrm{CHI}$ '13, and the recipient of the ACM/SIGCHI Lifetime Acheivement Service Award and a Doctor Honoris Causa from Aarhus University. She has published over 200 peer-reviewed research articles in the area of HumanComputer Interaction. Her current research interests include the design of interactive tools, using human-computer partnerships, to support creativity, as well as participatory and generative research and design methods.

Ross Graeber is a Senior Software Engineer at Schlumberger HPTC. He focuses on User Experience design for service applications in energy exploration and production. Ross has interest in how social communities influence the development of games and how collaboration outside the game itself can effect play. He currently leads and plays multiple online versions of traditionally tabletop games. 


\section{References}

[1] lan Bogost. 2016. Play Anything: The Pleasure of Limits, the Uses of Boredom, \& the Secret of Games. Basic Books.

[2] Nicholas D. Bowman, Rachel Kowert, and Christopher J. Ferguson. 2015. The Impact of Video Game Play on Human (and Orc) Creativity. In Video Games and Creativity, Garo P. Green and James C. Kaufman (Eds.). Academic Press, San Diego, 39 - 60. DOI : http://dx.doi.org/https : //doi.org/10.1016/B978-0-12-801462-2.00002-3

[3] John Butterfield, Philip Parker, and David Honigmann. 1982. What is Dungeons and Dragons? Puffin Books.

[4] Erin A. Carroll, Celine Latulipe, Richard Fung, and Michael Terry. 2009. Creativity Factor Evaluation: Towards a Standardized Survey Metric for Creativity Support. In Proceedings of the Seventh ACM Conference on Creativity and Cognition (C\&C '09). ACM, New York, NY, USA, 127-136. DOI : http://dx.doi.org/10.1145/1640233.1640255

[5] Mihaly Csikszentmihalyi and Isabella Csikszentmihalyi. 1975. Beyond Boredom and Anxiety: Experiencing Flow in Work and Play. Vol. 721. Jossey-Bass San Francisco.

[6] Gary Alan Fine. 2002. Shared fantasy: Role playing games as social worlds. University of Chicago Press.

[7] Ronald A. Finke, Thomas B. Ward, and Steven M. Smith. 1992. Creative Cognition: Theory, Research, and Applications. MIT Press.

[8] Gerhard Fischer. 2005. Distances and Diversity: Sources for Social Creativity. In Proceedings of the 5th Conference on Creativity \& Cognition (C\&C '05). ACM,
New York, NY, USA, 128-136. DOI :

http://dx.doi.org/10.1145/1056224.1056243

[9] Jonas Frich, Michael Mose Biskjaer, and Peter Dalsgaard. 2018. Twenty Years of Creativity Research in Human-Computer Interaction: Current State and Future Directions. In Proceedings of the 2018 Designing Interactive Systems Conference (DIS '18). ACM, New York, NY, USA, 1235-1257. DOI : http://dx.doi.org/10.1145/3196709.3196732

[10] Lisa Gjedde. 2013. Role game playing as a platform for creative and collaborative learning. In European Conference on Games Based Learning. Academic Conferences International Limited, 190.

[11] William A. Hamilton, Oliver Garretson, and Andruid Kerne. 2014. Streaming on Twitch: Fostering Participatory Communities of Play Within Live Mixed Media. In Proceedings of the 32nd Annual ACM Conference on Human Factors in Computing Systems (CHI '14). ACM, New York, NY, USA, 1315-1324. DOI : http://dx.doi.org/10.1145/2556288.2557048

[12] Karla R. Hamlen. 2009. Relationships between Computer and Video Game Play and Creativity among Upper Elementary School Students. Journal of Educational Computing Research 40, 1 (2009), 1-21. DOI:http://dx.doi.org/10.2190/EC.40.1.a

[13] Eva Hornecker, Hal Eden, and Eric Scharff. 2002. In MY situation I would dislike THAAAT! - Role Play as Assessment Method for Tools Supporting Participatory Planning. In Proceedings of PDC 2002.

[14] James C. Kaufman and Ronald A. Beghetto. 2009. Beyond Big and Little: The Four C Model of Creativity. Review of General Psychology 13, 1 (2009), 1-12. DOI : http://dx.doi.org/10.1037/a0013688 
[15] Andruid Kerne, Andrew M. Webb, Steven M. Smith, Rhema Linder, Nic Lupfer, Yin Qu, Jon Moeller, and Sashikanth Damaraju. 2014. Using Metrics of Curation to Evaluate Information-Based Ideation. ACM Trans. Comput.-Hum. Interact. 21, 3, Article 14 (June 2014), 48 pages. DOI: http://dx.doi.org/10.1145/2591677

[16] Sage LaTorra and Adam Koebel. 2013. Dungeon World. RNDM Games.

[17] Pascal Lessel, Michael Mauderer, Christian Wolff, and Antonio Krüger. 2017a. Let's Play My Way:

Investigating Audience Influence in User-Generated Gaming Live-Streams. In Proceedings of the 2017 ACM International Conference on Interactive Experiences for TV and Online Video (TVX '17). ACM, New York, NY, USA, 51-63. DOI :

http://dx.doi.org/10.1145/3077548.3077556

[18] Pascal Lessel, Alexander Vielhauer, and Antonio Krüger. 2017b. Expanding Video Game Live-Streams with Enhanced Communication Channels: A Case Study. In Proceedings of the 2017 CHI Conference on Human Factors in Computing Systems (CHI '17). ACM, New York, NY, USA, 1571-1576. DOI : http://dx.doi.org/10.1145/3025453.3025708

[19] Daniel Mackay. 2001. The Fantasy Role-Playing Game: A New Performing Art. McFarland \& Company, Inc.

[20] Nicholas J. Mizer. 2015. The Greatest Unreality: Tabletop Role-Playing Games and the Experience of Imagined Worlds. Ph.D. Dissertation. Texas A\&M University.

[21] Melissa J. Rogerson, Martin Gibbs, and Wally Smith. 2016. "I Love All the Bits": The Materiality of Boardgames. In Proceedings of the $2016 \mathrm{CHI}$
Conference on Human Factors in Computing Systems (CHI '16). ACM, New York, NY, USA, 3956-3969.

DOI: http://dx.doi.org/10.1145/2858036.2858433

[22] Melissa J. Rogerson, Martin R. Gibbs, and Wally Smith. 2018. Cooperating to Compete: The Mutuality of Cooperation and Competition in Boardgame Play. In Proceedings of the $2018 \mathrm{CHI}$ Conference on Human Factors in Computing Systems (CHI '18). ACM, New York, NY, USA, Article 193, 13 pages. DOI : http://dx.doi .org/10.1145/3173574.3173767

[23] Mark A Runco. 1991. Divergent thinking. Ablex Publishing Corporation.

[24] Sandra W. Russ, Andrew L. Robins, and Beth A. Christiano. 1999. Pretend Play: Longitudinal Prediction of Creativity and Affect in Fantasy in Children. Creativity Research Journal 12, 2 (1999), 129-139. DOI :

http://dx.doi.org/10.1207/s15326934crj1202_5

[25] Katie Salen and Eric Zimmerman. 2004. Rules of Play: Game Design Fundamentals. MIT Press, Cambridge, MA, USA.

[26] R Keith Sawyer and Stacy DeZutter. 2009. Distributed creativity: How collective creations emerge from collaboration. Psychology of Aesthetics, Creativity, and the Arts 3, 2 (2009), 81-92. DOI : http://dx.doi.org/10.1037/a0013282

[27] Jana Schumann, Patrick C. Shih, David F. Redmiles, and Graham Horton. 2012. Supporting Initial Trust in Distributed Idea Generation and Idea Evaluation. In Proceedings of the 17th ACM International Conference on Supporting Group Work (GROUP '12). ACM, New York, NY, USA, 199-208. DOI :

http://dx.doi.org/10.1145/2389176.2389207 
[28] Joseph Seering, Saiph Savage, Michael Eagle, Joshua Churchin, Rachel Moeller, Jeffrey P. Bigham, and Jessica Hammer. 2017. Audience Participation Games: Blurring the Line Between Player and Spectator. In Proceedings of the 2017 Conference on Designing Interactive Systems (DIS '17). ACM, New York, NY, USA, 429-440. DOI :

http://dx.doi.org/10.1145/3064663.3064732

[29] Jami J. Shah, Steve M. Smith, and Noe

Vargas-Hernandez. 2003. Metrics for measuring ideation effectiveness. Design studies 24, 2 (2003), 111-134.

[30] Jaakko Stenros and Markus Montola. 2011. The Making of Nordic Larp: Documenting a Tradition of Ephemeral Co-Creative Play.. In DiGRA Conference.

[31] Andrew M. Webb, Philip Tchernavskij, and Wendy E. Mackay. 2019. Artifact-Mediated Improvisation in Tabletop Role-Playing Games. In submission to Proceedings of ACM Creativity \& Cognition 2019. 